\title{
Moderate HER2 expression as a prognostic factor in hormone receptor positive breast cancer
}

\author{
Holm Eggemann 1,", Tanja Ignatov1,, Elke Burger ${ }^{2}$, Eva Johanna Kantelhardt ${ }^{3}$, \\ Franziska Fettke ${ }^{1}$, Christoph Thomssen ${ }^{3}$, Serban Dan Costa ${ }^{1}$ and Atanas Ignatov ${ }^{1}$ \\ ${ }^{1}$ Department of Obstetrics and Gynecology, and ${ }^{2}$ Institute of Biometry and Medical Informatics, Otto-von-Guericke \\ University, Gerhart-Hauptmann Straße 35, 39108 Magdeburg, Germany \\ ${ }^{3}$ Department of Gynecology, Martin Luther University, Halle (Saale), Germany \\ *(H Eggemann and T Ignatov contributed equally to this work)
}

\author{
Correspondence \\ should be addressed \\ to A Ignatov \\ Email \\ atanas.ignatov@med.ovgu.de
}

\begin{abstract}
Overexpression and/or amplification of human epidermal growth factor receptor 2 (HER2) is associated with poor prognosis in breast cancer and predicts response to anti-HER2 therapy in breast cancer. The prognostic relevance of moderate expression of HER2 is unclear. Data of 9872 patients with primary nonmetastatic breast cancer from the cancer registries of Magdeburg and Halle, Germany, were analyzed retrospectively. A total of 5907 patients with complete data sets including follow-up were eligible for analysis. HER2 status was determined as recommended by international guidelines. Of 5907 patients investigated, $5023(68.4 \%)$ had HER2 0 and $1+$ expression and $884(12.0 \%)$ had HER2 $(2+) /$ HER2 - expression. Patients with hormone receptor positive $(\mathrm{HR}+)$ and HER2 $(2+)$ tumors had a shorter median disease-free survival (DFS; $P<0.0001)$ and breast cancer specific survival (BCSS; $P=0.019)$ than HR + patients with HER2 $(0 / 1+)$ tumors. Among patients with HR breast cancer there was no significant difference between HER2 $(2+)$ and HER2 $(0 / 1+)$ tumors. In multivariate analysis after adjustment for other prognostic factors, HER2 (2+) status remained an unfavorable prognostic factor for DFS (hazard ratio $(H R)=1.217,95 \%$ $\mathrm{Cl}=1.052-1.408 ; P=0.008)$ but not for $\mathrm{BCSS}(\mathrm{HR}=1.045,95 \% \mathrm{Cl}=0.926-1.178 ; P=0.474)$. The HER2 $(2+)$ status is an unfavorable prognostic factor for survival of patients with HR + breast cancer. The impact of anti-HER2 therapy in this group of patients should be evaluated.
\end{abstract} Key Words

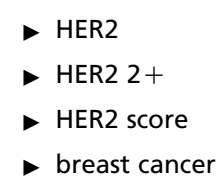

Endocrine-Related Cancer (2015) 22, 725-733

\section{Introduction}

The human epidermal growth factor receptor 2 (HER2) is a cell surface transmembrane receptor. HER2 amplification occurs in 20-30\% of invasive breast cancers (Akiyama et al. 1986, Slamon et al. 1987, 1989, Gasparini et al. 1994) and is associated with poor prognosis (Slamon et al. 1987, Ross \& Fletcher 1998, Berry et al. 2000, Gennari et al. 2008). The HER2 status is not only a prognostic but also a predictive factor for response to the anti-HER2 therapy, e.g., trastuzumab (Slamon et al. 2011). Based on standardized criteria, HER2 expression has been divided on the basis of immunohistochemical (IHC) results into the following groups: $0,1+, 2+$, and $3+$ (Jacobs et al. 1999). It is believed that HER2 tumors scored 0 and $1+$ do not respond to trastuzumab therapy. On the contrary, a HER2 $(3+)$ status implies strong expression of the receptor and is highly predictive for a response to this drug

Published by Bioscientifica Ltd. 
(Ross \& Fletcher 1998, Wolff et al. 2007). The moderate group of HER2 $(2+)$ cancers requires an additional gene amplification assay (e.g., fluorescent in situ hybridization (FISH) or silver in situ hybridization (SISH) respectively) to identify patients who overexpress HER2 and benefit from anti-HER2 therapy (Ross \& Fletcher 1998). Interestingly, in retrospective analysis with small patient cohorts, the moderate $(2+)$ and low $(1+)$ HER2 expression has been shown to be a negative prognostic survival factor for breast cancer patients (Gilcrease et al. 2009, Rossi et al. 2012). Patients with negative HER2 (0) expression demonstrated significantly longer median survival compared to patients with low HER2 $(1+)$ and moderate HER2 $(2+)$ expression respectively. Thus, the prognostic value of moderate HER2 $(2+)$ expression requires reevaluation. In this study we retrospectively analyzed 5907 patients with breast cancer. The HER2 status was compared with clinical and pathological characteristics. The clinical outcome of patients with moderate HER2 $(2+)$ expression was compared with that of HER2 negative $(0 / 1+)$ patients.

\section{Patients and methods}

\section{Patients}

We investigated cases of female breast cancer included in the regional cancer registry of Saxony-Anhalt, federal state of Germany. The tumor registry contains information on diagnosis, age, tumor stage, receptor status, tumor grading, lymph node status, date of diagnosis, date of disease recurrence, date of death, and the treatment regimens used. In our cohort study we analyzed women with primary non-metastatic breast cancer diagnosed between 2003 and 2013 in nine hospitals in Saxony-Anhalt, federal state of Germany: University Hospital Magdeburg, University Hospital Halle, Harzklinikum Dorothea Christiane Erxleben, Johanniter Clinic Genthin-Stendal, HELIOS Clinic Burg, and the AMEOS Clinics in Aschersleben, Halberstadt, Haldensleben, and Schönebeck.

The primary outcome of this study was disease-free survival (DFS) of patients with HER2 $(2+)$ breast cancer compared to patients with HER2 $(0 / 1+)$ breast cancer. Secondary endpoints were DFS of patients with hormone receptor positive $(\mathrm{HR}+) / \mathrm{HER} 2(2+)$ breast cancer compared to patients with HR+/HER2 $(0 / 1+)$ breast cancer; DFS of patients with HR-/HER2 $(2+)$ breast cancer compared to patients with HR-/HER2 (0/1+) breast cancer; breast cancer specific survival (BCSS) of patients with HER2 $(2+)$ breast cancer compared to patients with HER2 $(0 / 1+)$ breast cancer; BCSS of patients with HR +/HER2 $(2+)$ breast cancer compared to patients with HR +/HER2 $(0 / 1+)$ breast cancer; and BCSS of patients with HR-/HER2 $(2+)$ compared to patients with HR - /HER2 $(0 / 1+)$ breast cancer.

We identified 9872 female patients with primary nonmetastatic invasive breast cancer. In 2526 cases the HER2 status was unknown and these patients were excluded from this study (Fig. 1). Another 1329 patients with HER2

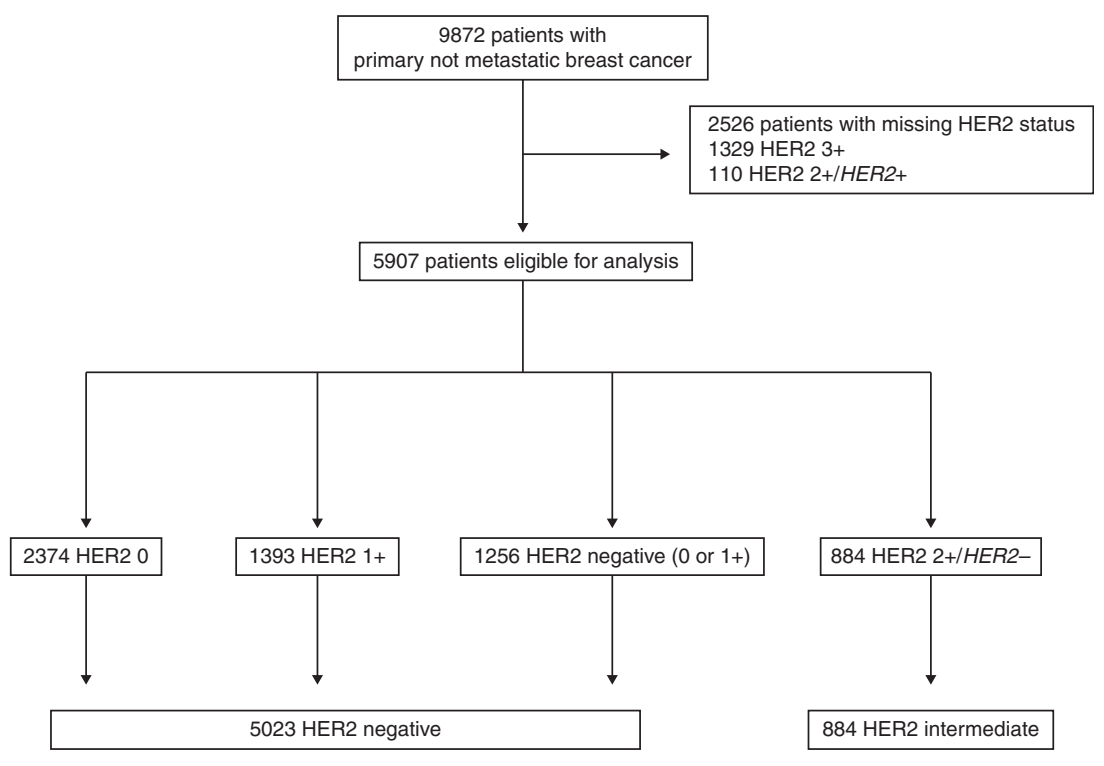

Figure 1

Study cohort. HER2, human epidermal growth factor receptor 2. 
$(3+)$ and 110 patients with HER2 $(2+) / H E R 2+$ expression were also excluded. A total of 5907 eligible cases were included in the study. The follow-up period ended with the patient's death or with the latest available information in the tumor registry. This study was approved by the Research and Ethical Committee of Otto-von-Guericke University, Magdeburg, Germany. Patients gave written informed consent for data transfer to the tumor registry.

Table 1 Patient and tumor characteristics

\begin{tabular}{|c|c|c|c|c|}
\hline \multirow[b]{2}{*}{ Characteristics } & \multirow[b]{2}{*}{ No. of patients } & \multicolumn{2}{|c|}{ HER2 status } & \multirow[b]{2}{*}{$P$ value } \\
\hline & & Negative, $n(\%)$ & Moderate, $n(\%)$ & \\
\hline Total & 5907 & 5023 & 884 & \\
\hline Age (range) & & 63 (24-97) & $63(25-101)$ & 0.103 \\
\hline \multicolumn{5}{|l|}{ Menopausal status } \\
\hline Premenopausal & 1175 & $994(19.9)$ & $181(20.6)$ & 0.648 \\
\hline Postmenopausal & 4695 & $3997(80.1)$ & 698 (79.4) & \\
\hline \multicolumn{5}{|l|}{ Tumor size $(\mathrm{cm})$} \\
\hline$\leq 2$ & 4741 & 4048 (86.6) & $693(83.4)$ & 0.017 \\
\hline$>2$ & 627 & $627(13.4)$ & 138 (16.6) & \\
\hline Missing & 539 & 348 & 191 & \\
\hline \multicolumn{5}{|l|}{ Lymph node status } \\
\hline Negative & 3820 & $3283(68.0)$ & 537 (62.9) & 0.004 \\
\hline Positive & 1863 & $1546(32.0)$ & $317(37.1)$ & \\
\hline Missing & 224 & 194 & 30 & \\
\hline \multicolumn{5}{|l|}{ Histotype } \\
\hline Ductal & 4592 & 3883 (77.4) & $709(80.3)$ & 0.019 \\
\hline Lobular & 790 & $675(13.5)$ & $115(13.0)$ & \\
\hline Mixed & 355 & $322(6.4)$ & $33(3.7)$ & \\
\hline Other & 164 & $138(2.8)$ & $26(2.9)$ & \\
\hline Missing & 6 & 6 & 0 & \\
\hline \multicolumn{5}{|l|}{ Grade } \\
\hline 1 & 1083 & 964 (19.5) & $119(13.8)$ & 0.0001 \\
\hline 2 & 3205 & $2730(55.4)$ & $475(55.1)$ & \\
\hline 3 & 1505 & $1237(25.1)$ & $268(31.1)$ & \\
\hline Missing & 114 & 92 & 22 & \\
\hline \multicolumn{5}{|l|}{$\mathrm{Ki}-67$} \\
\hline$\leq 14$ & 544 & $452(43.7)$ & $92(23.2)$ & 0.0001 \\
\hline$>14$ & 887 & $583(56.3)$ & $304(76.8)$ & \\
\hline Missing & 4476 & 3988 & 488 & \\
\hline \multicolumn{5}{|l|}{ ER status } \\
\hline Negative & 958 & $852(17.8)$ & $106(12.5)$ & 0.0001 \\
\hline Positive & 4684 & 3938 (82.2) & 746 (87.5) & \\
\hline Missing & 265 & 233 & 32 & \\
\hline \multicolumn{5}{|l|}{ PR status } \\
\hline Negative & 1403 & $1215(25.4)$ & $188(22.1)$ & 0.039 \\
\hline Positive & 4234 & $3570(74.6)$ & 664 (77.9) & \\
\hline Missing & 270 & 238 & 32 & \\
\hline \multicolumn{5}{|l|}{ Operative therapy } \\
\hline No & 2 & $2(0.01)$ & 0 & 0.0001 \\
\hline Breast conserving & 3934 & 3396 (69.7) & $538(62.8)$ & \\
\hline Mastectomy & 1791 & $1472(30.2)$ & 319 (37.2) & \\
\hline Missing & 180 & 153 & 27 & \\
\hline \multicolumn{5}{|l|}{ Radiation } \\
\hline No & 1687 & $1391(29.8)$ & $296(34.7)$ & 0.005 \\
\hline Yes & 3833 & 3277 (70.2) & $556(65.3)$ & \\
\hline Missing & 387 & 355 & 32 & \\
\hline \multicolumn{5}{|l|}{ Chemotherapy } \\
\hline No & 3107 & $2661(55.6)$ & $446(51.4)$ & 0.024 \\
\hline Yes & 2549 & 2099 (44.4) & $422(48.6)$ & \\
\hline Missing & 251 & 239 & 16 & \\
\hline \multicolumn{5}{|l|}{ Hormonal therapy } \\
\hline No & 2248 & $1888(40.0)$ & $360(41.6)$ & 0.386 \\
\hline Yes & 3433 & $2837(60.0)$ & $506(58.4)$ & \\
\hline Missing & 226 & 298 & 18 & \\
\hline
\end{tabular}




\section{HER2 status}

The HER2 status was assessed using the HercepTest (Hamburg, Germany) according to the manufacturer's instructions. The IHC staining of HER2 is based on the staining intensity and distribution (Jacobs et al. 1999). The HER2 status is grouped as follows: 0, no staining; $1+$, faint/barely perceptible membrane staining detected in $>10 \%$ of the tumor cells; $2+$, weak to moderate membrane staining $>10 \%$ of the tumor cells; and $3+$, strong, circumferential membrane staining in $>30 \%$ of tumor cells. Very recently new updated guidelines for HER2 determination have been published (Wolff et al. 2013). FISH or SISH testing is routinely used to assess the HER2 gene amplification in cases with moderate HER2 $(2+)$ expression. Patients with positive HER2 expression defined as HER2 $(3+)$ or HER2 $(2+)$ by IHC and positive HER2 amplification by FISH or SISH (HER2 $(2+) / H E R 2+)$ ( $n=1439,19.6 \%)$ were excluded (Fig. 1). The remaining 5907 patients were divided into two main groups (Fig. 1): HER2 negative $(n=5023,68.4 \%)$ and HER2 moderate defined as HER2 $(2+)$ by IHC without gene amplification $(n=884,12.0 \%)$. The HER2 negative group consisted of 2374 (47.3\%) HER2 (0), 1393 (27.7\%) HER2 (1+), and 1256 (25.0\%) HER2 negative cases with no exact scoring available $(0$ or $1+)$. The HER 2 moderate group consisted of $884(12.0 \%)$ cases with moderate expression according to IHC (HER2 $(2+)$ and with HER2 - by FISH or SISH (HER2 $(2+) / H E R 2-)$.

\section{Statistical analysis}

The statistical calculations were performed using SPSS version 21.0 (SPSS). The association between HER2 status and clinical and pathological variables was assessed using the $\chi^{2}$ test or Fisher's exact test. The DFS and BCSS probability distribution was studied by the KaplanMeier method. The equality of survival curves was tested by the log rank test. DFS was defined as the time between primary diagnosis and disease recurrence of all types as well as breast cancer specific death. BCSS was defined as the time between primary diagnosis and breast cancer specific death. Patients who died of other causes or patients lacking follow-up data were censored. Univariate Cox proportional hazards regression analysis was used to identify significant prognostic factors and then the prognostic significance was evaluated using multivariate analysis. The statistical analyses were two sided and $P$ values of $<0.05$ were considered statistically significant.

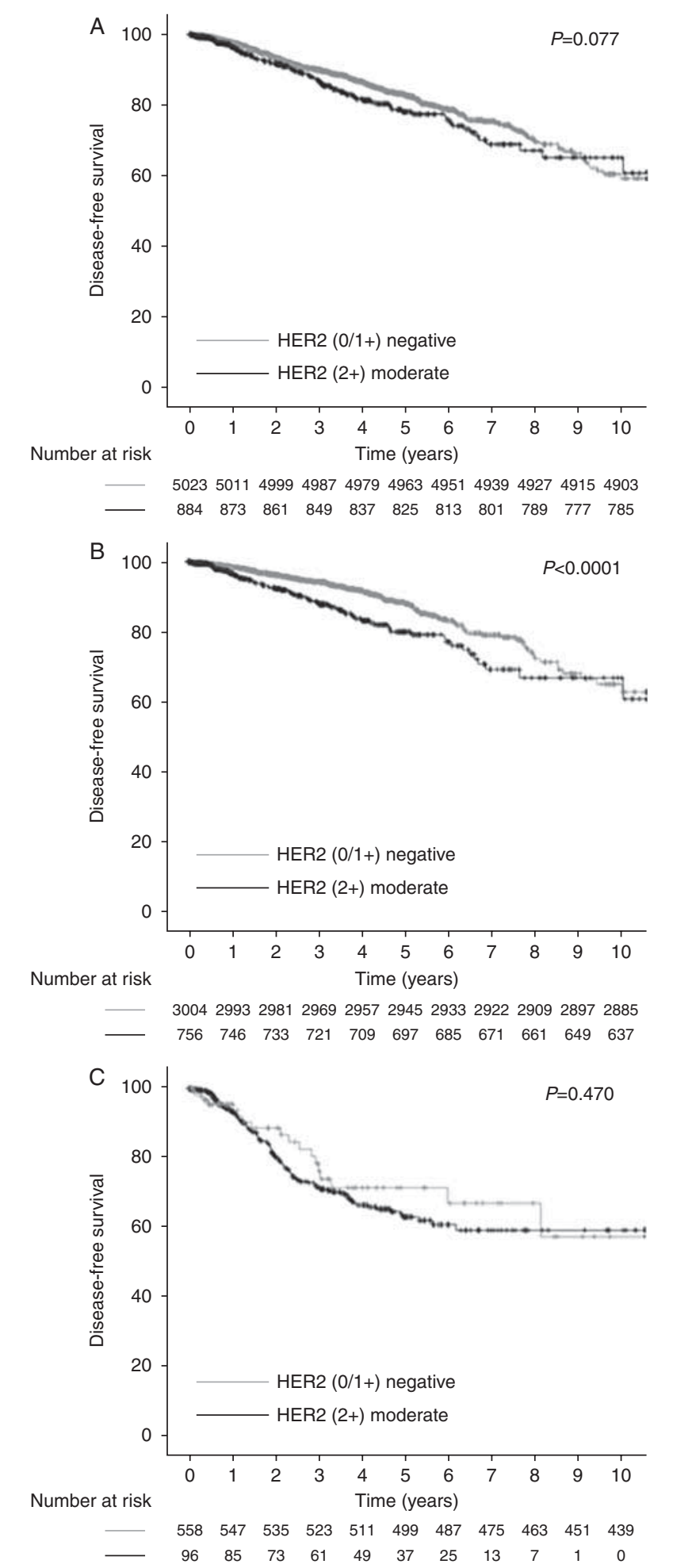

\section{Figure 2}

DFS probability according to HER2 status. DFS in the whole cohort (A), HR+ (B), and HR - (C) breast cancer is demonstrated. The log rank test was used to calculate the $P$ value. HER2, human epidermal growth factor receptor 2; DFS, disease-free survival.

Published by Bioscientifica Ltd 


\section{Results}

\section{Study design}

Between January 2003 and December 2013, 9872 women with primary non-metastatic invasive breast cancer underwent medical treatment in nine hospitals. Patients with unknown HER2 status $(n=2526)$ and patients with positive HER2 expression defined as HER2 $(3+)$ or HER2 $(2+)$ by IHC and positive HER $2+$ amplification by FISH or SISH (HER2 $(2+) / H E R 2+)(n=1439)$ had to be excluded (Fig. 1). The remaining 5907 patients with a median age of 63 years (range 19-101 years) were eligible for analysis. Patients were divided into two groups based on their HER2 expression and HER2 gene amplification (Fig. 1). Table 1 summarizes patient and tumor characteristics according to the HER2 IHC-score. Clinical data including surgery, chemotherapy, and hormonal therapy were also analyzed with regard to the HER2 score.

\section{HER2 status and patient and tumor characteristics}

Patient and tumor characteristics showed significant differences between the two groups. Moderate HER2 $(2+)$ expression was associated with larger tumor size $(P<0.0001)$, positive lymph node status $(P=0.017)$, invasive ductal histologic type $(P=0.019)$, higher tumor grade $(P<0.0001)$, increased expression of Ki-67, lymph node metastases $(P=0.004)$ and positive estrogen receptor $(\mathrm{ER})(P<0.0001)$ and progesterone receptor $(\mathrm{PR})$ status $(P=0.039)$. Patients with moderate HER2 $(2+)$ expression were more likely to receive chemotherapy $(P=0.024)$ but significantly less likely to receive breast conserving surgery $(P<0.0001)$ followed by radiation $(P=0.005)$ in comparison to the patients with HER2 $(0 / 1+)$ negative expression.

\section{HER2 status and survival}

HER2 $(2+)$ moderate expression appeared to be a worse prognosticator for DFS in comparison to the HER2 $(0 / 1+)$ negative cases in view of the first 10 years following diagnosis, without statistical significance (Fig. 2A, $P=0.072$ ). Interestingly, analysis of DFS according to HR status showed that HER2 $(2+)$ moderate expression is an unfavorable prognostic factor in $\mathrm{HR}+$ cases (Fig. 2B, $P<0.0001$ ) but not in HR - cases (Fig. 2C, $P=0.470$ ). HER2 $(2+)$ moderate status was not associated with BCSS in the whole cohort (Fig. 3A, $P=0.659$ ). Patients with $\mathrm{HR}+$ and moderate HER2 $(2+)$ expression had been found to be associated with shorter median BCSS than HR + and HER2

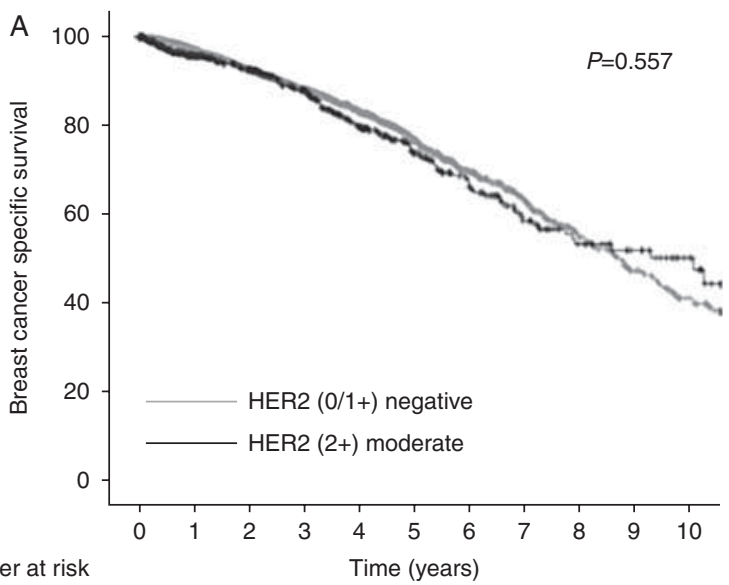

$\begin{array}{ccccccccc}\text { Number at risk } & \text { Time (years) } \\ & 50235011499949874975496349514939492749154903\end{array}$

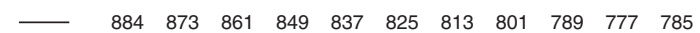

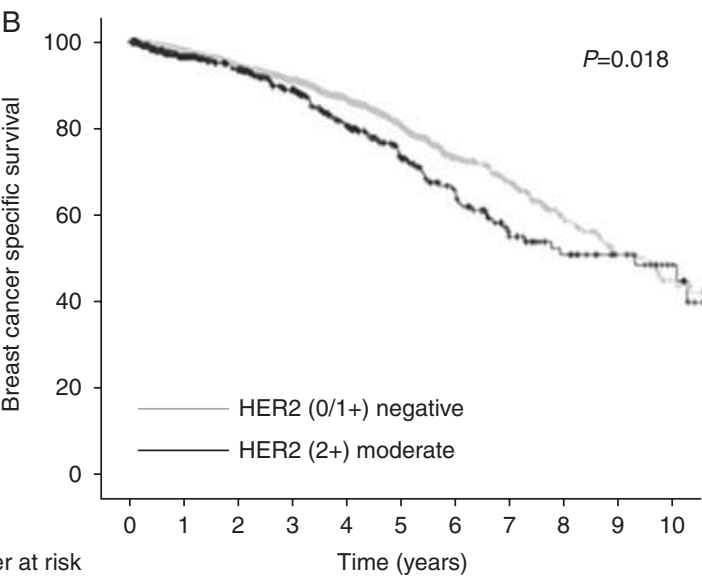

Number at risk

30042993298129692957294529332922290928972885
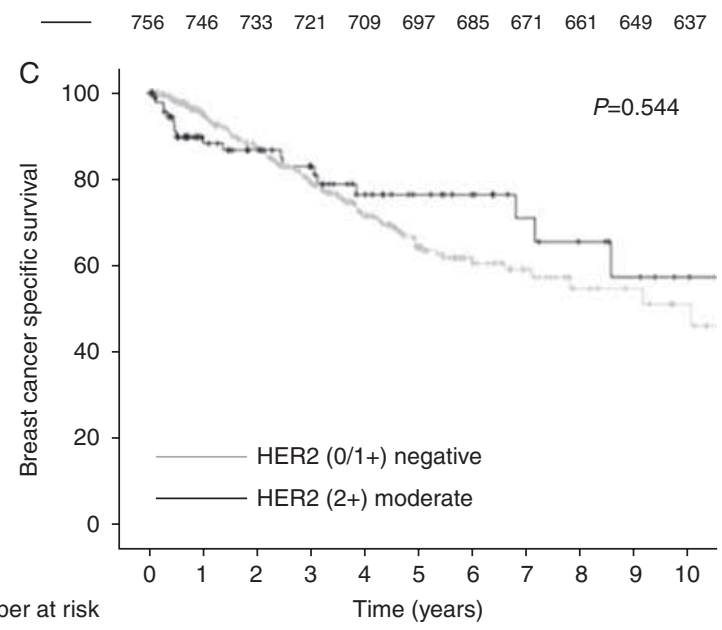

Number at risk

$\begin{array}{cccccccccccc}558 & 547 & 535 & 523 & 511 & 499 & 487 & 475 & 463 & 451 & 439 \\ & 96 & 85 & 73 & 61 & 49 & 37 & 25 & 13 & 7 & 1 & 0\end{array}$

\section{Figure 3}

BCSS probability according to HER2 status. BCSS in the whole cohort (A), $\mathrm{HR}+(\mathrm{B})$, and $\mathrm{HR}-(\mathrm{C})$ breast cancer is demonstrated. The log rank test was used to calculate the $P$ value. HER2, human epidermal growth factor receptor 2; BCSS, breast cancer specific survival.

Published by Bioscientifica Ltd 
Table 2 Uni- and multivariate analysis of disease-free survival in hormone receptor positive patients

\begin{tabular}{l} 
Parameter \\
\hline HER2 \\
Negative vs moderate \\
Age (years) \\
$\leq 45$ vs $>45$ \\
Menopausal status \\
Pre vs post \\
Tumor size (cm) \\
$\leq 2$ vs $>2$ \\
Lymph node status \\
Negative vs positive \\
Histologic grade \\
1 vs 2 and 3 \\
Operative therapy \\
Breast conserving vs mastectomy \\
Radiation \\
No vs yes \\
Chemotherapy \\
No vs yes \\
Hormonal therapy \\
No vs yes
\end{tabular}

\begin{tabular}{|c|c|c|}
\hline \multicolumn{3}{|c|}{ Univariate analysis } \\
\hline Hazard ratio & $95 \% \mathrm{Cl}$ & $P$ value \\
\hline 1.272 & $1.112-1.454$ & 0.0001 \\
\hline 0.500 & $0.365-0.685$ & 0.0001 \\
\hline 0.875 & $0.720-1.065$ & 0.183 \\
\hline 3.420 & $2.838-4.123$ & 0.0001 \\
\hline 2.799 & $2.357-3.325$ & 0.0001 \\
\hline 2.504 & $1.806-3.470$ & 0.0001 \\
\hline 2.079 & $1.753-2.465$ & 0.0001 \\
\hline 0.964 & $0.809-1.150$ & 0.688 \\
\hline 1.580 & $1.331-1.875$ & 0.0001 \\
\hline 0.762 & $0.615-0.946$ & 0.014 \\
\hline
\end{tabular}

\begin{tabular}{|c|c|c|}
\hline \multicolumn{3}{|c|}{ Multivariate analysis } \\
\hline Hazard ratio & $95 \% \mathrm{Cl}$ & $P$ value \\
\hline 1.216 & $1.056-1.400$ & 0.007 \\
\hline 0.493 & $0.280-0.870$ & 0.015 \\
\hline 1.281 & $0.883-1.859$ & 0.192 \\
\hline 1.709 & $1.244-2.347$ & 0.001 \\
\hline 1.738 & $1.291-2.340$ & 0.0001 \\
\hline 2.707 & $1.662-4.409$ & 0.0001 \\
\hline 1.332 & $1.030-1.805$ & 0.039 \\
\hline 1.010 & $0.735-1.389$ & 0.950 \\
\hline 1.078 & $0.819-1.419$ & 0.790 \\
\hline 0.877 & $0.646-1.191$ & 0.401 \\
\hline
\end{tabular}

$(0 / 1+)$ negative patients (Fig. 3B, $P=0.018)$. In $\mathrm{HR}-$ patients, HER2-status had no influence on BCSS (Fig. 3C, $P=0.544)$.

Univariate analysis revealed that HER2 $(2+)$ moderate status was a prognostic factor for poor DFS (hazard ratio $(\mathrm{HR})=1.272$, 95\% CI $=1.112-1.454 ; P<0.0001$; Table 2) and $\mathrm{BCSS}(\mathrm{HR}=1.139,95 \% \mathrm{CI}=1.022-1.270 ; P=0.019$; Table 3 ) in $\mathrm{HR}+$ breast cancer patients. In $\mathrm{HR}-$ breast cancer there was no significant difference (Table 4). After adjustment for patients' age, menopausal status, tumor size, lymph node status, tumor grade, operative therapy, radiation, chemotherapy, and hormone therapy, multivariate analysis rendered HER2 $(2+)$ as an independent, unfavorable prognostic factor for DFS $(\mathrm{HR}=1.217$, 95\% CI=1.052-1.408; $P=0.008$; Table 2) but not for BCSS in HR + breast cancer patients $(\mathrm{HR}=1.045,95 \%$

Table 3 Uni- and multivariate analysis of breast cancer specific survival in hormone receptor positive patients

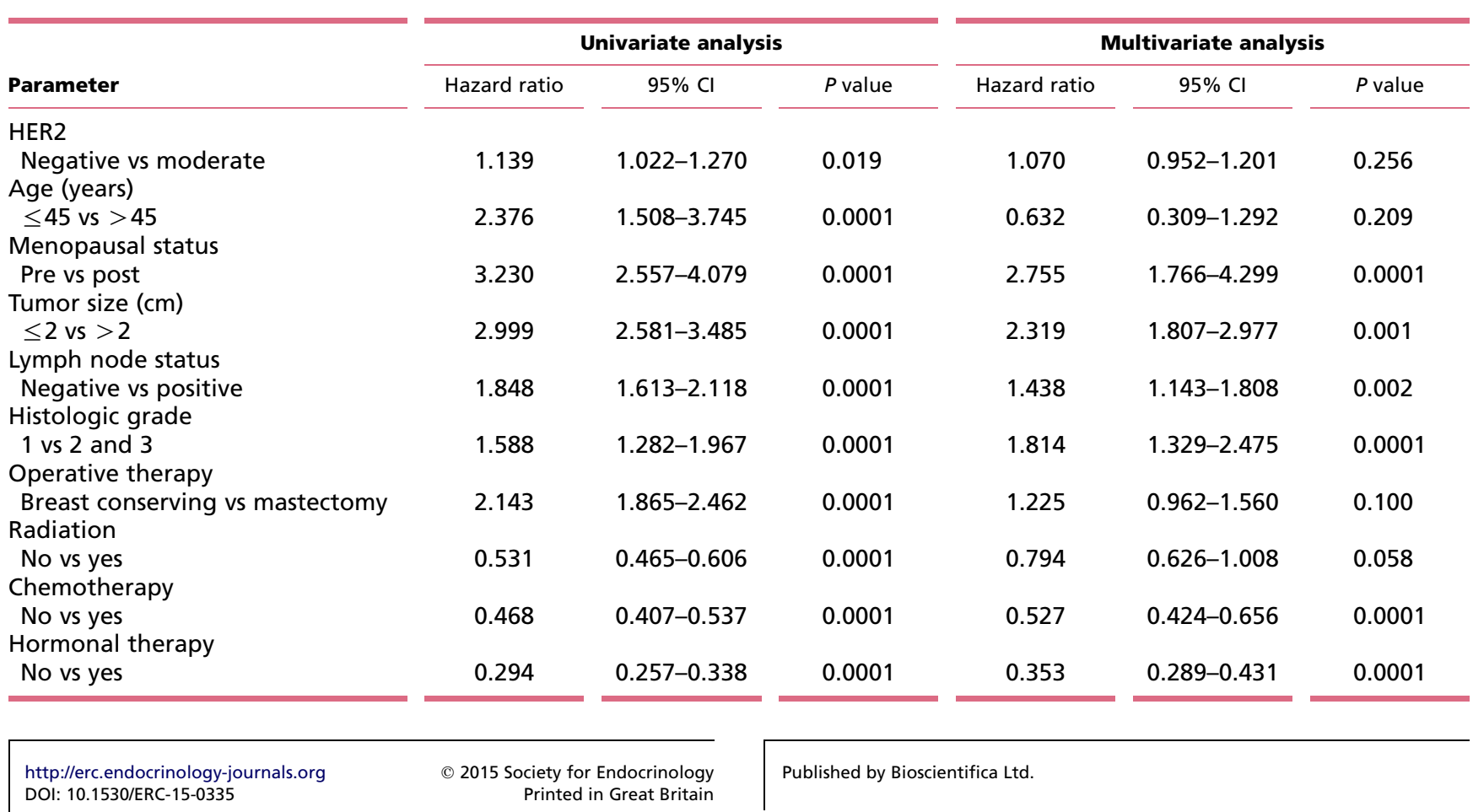


Table 4 Univariate analysis of disease-free survival and breast cancer specific survival in hormone receptor negative patients

\begin{tabular}{l} 
Parameter \\
\hline HER2 \\
Negative vs moderate \\
Age (years) \\
$\leq 45$ vs $>45$ \\
Menopausal status \\
Pre vs post \\
Tumor size (cm) \\
$\leq 2$ vs $>2$ \\
Lymph node status \\
Negative vs positive \\
Histologic grade \\
1 vs 2 and 3 \\
Operative therapy \\
Breast conserving vs mastectomy \\
Radiation \\
No vs yes \\
Chemotherapy \\
No vs yes \\
Hormonal therapy \\
No vs yes
\end{tabular}

\begin{tabular}{|c|c|}
\hline & DFS \\
\hline Hazard ratio & $95 \% \mathrm{Cl}$ \\
\hline 0.913 & $0.714-1.16$ \\
\hline 0.484 & $0.595-1.20$ \\
\hline 0.852 & $0.664-1.09$ \\
\hline 2.423 & $1.829-3.20 \mathrm{~s}$ \\
\hline 2.615 & $2.075-3.297$ \\
\hline 1.847 & $0.592-5.765$ \\
\hline 1.928 & $1.529-2.430$ \\
\hline 0.697 & $0.545-0.892$ \\
\hline 1.010 & $0.737-1.38$ \\
\hline 1.401 & $0.984-1.99$ \\
\hline $\begin{array}{l}<45 \text { years old } \\
\text { invasion, } \\
\text { ere addition } \\
\text { (Table } 2 \text { ). } \\
\text { tive lymph } \\
\text { the admini } \\
\text { nd hormon } \\
\text { Table } 3 \text { ). }\end{array}$ & $\begin{array}{l}\text { increased } \\
\text { gh histo- } \\
\text { unfavor- } \\
\text { nopausal } \\
\text { de status, } \\
\text { ation of } \\
\text { therapy }\end{array}$ \\
\hline
\end{tabular}

$\mathrm{CI}=0.926-1.178 ; P=0.474)$. Age $<45$ years old, increased tumor size, positive lymph node invasion, high histological grade, and mastectomy were additional unfavorable prognostic factors for DFS (Table 2). Menopausal status, increased tumor size, positive lymph node status, higher histological grade, and the administration of radiotherapy, chemotherapy, and hormonal therapy were associated with worse BCSS (Table 3).

\section{Discussion}

This is the largest study of its kind investigating the impact of HER2 $(2+)$ moderate expression on breast cancer survival. Our data provide evidence that tumors with moderate HER2 $(2+)$ expression with no gene amplification differ from cases with negative or low HER2 expression $(0 / 1+)$. As expected HER2 positivity $(3+)$ was associated with a poor clinical outcome and aggressive tumor behavior, which is consistent with recently published data (Templeton et al. 2014). In our study, $\mathrm{HR}+$ breast cancer patients with tumors displaying moderate HER2 $(2+)$ expression had a poorer DFS but not BCSS compared with low $(1+)$ or negative (0) HER2 expression, confirming previous findings from smaller cohort studies (Gilcrease et al. 2009, Iorfida et al. 2012). In other studies, HER2 $(2+)$ was a prognostic factor only in lymph node positive breast cancer (Menard et al. 2008). However, the impact of moderate HER2 $(2+)$ expression on DFS by multivariate analysis after adjustment for other prognostic factors has been not shown yet (Menard et al. 2008). HER $2(2+)$ moderate status is defined as $\sim 500000$ detectable HER2 receptors on the cell surface (Ross \& Fletcher 1998) required for the activation of underlying intracellular HER2 pathways to drive tumor growth and invasiveness. This hypothesis is supported by the finding that even low levels of HER2 $(1+)$ expression involving 100000 cell surface receptors (Ross \& Fletcher 1998) could be associated with a poor outcome (Camp et al. 2003, Gilcrease et al. 2009, Iorfida et al. 2012). According to our data, HER2 $(1+)$ tumors seem to have characteristics between HER2 (0) and HER2 $(2+)$ cancers suggesting a possible linear correlation between HER2 expression and tumor behavior. Such results have been observed for prostate cancer granted that HER2 overexpression is a rare phenomenon (Minner et al. 2010). Tumors with low or moderate expression of HER $2(2+)$ might be more sensitive to different growth factors stimulating breast cancer cells because HER2 signaling is a key factor in breast cancer proliferation (Ross \& Fletcher 1998). Interestingly, in our survey moderate expression of HER2 $(2+)$ receptor was identified as an unfavorable prognostic factor in patients with HR + tumors but not in those with HRtumors. As already demonstrated, HER2 expression is inversely related to the expression of HR (ER and PR) and is associated with endocrine resistance (Ross \& Fletcher 1998, Massarweh et al. 2008). One might speculate that low/moderate expression of HER2 indicates some activity of the HER2 pathway and thus an existing influence on

Published by Bioscientifica Ltd 
growth and proliferation via cross-talk with ER signaling. Notably, in our study HER2 expression was associated with increased proliferative features of the tumors: increased Ki-67 expression and reduced grade of proliferation.

HER2 overexpression is routinely used to predict response to anti-HER2 therapy and at present only patients with an IHC score $3+$ and gene amplification should receive anti-HER2 therapy (Goldhirsch et al. 2013). It has been demonstrated that tumors with moderate HER2 $(2+)$ expression without gene amplification do not respond to trastuzumab therapy (Slamon et al. 2011, Goldhirsch et al. 2013). However, recently published data suggest that a small number of patients with lower levels of HER2 $(1+)$ may benefit from anti-HER2 treatment (Paik et al. 2008, Perez et al. 2010).

The association of low HER2 $(1+)$ expression with patient survival has been investigated in a limited number of small sample-sized retrospective studies. Menard et al. (2008) conducted a retrospective study and were able to show that the HER2 $(2+)$ status is associated with increased recurrence rates in patients with positive lymph-nodes. Notably, their cohort study identified $24.1 \%$ patients as HER2 $(2+)$, whereas our cohort study identified only $12 \%$ patients as HER2 $(2+)$. This difference might be due to the fact that Menard et al. made no distinction between HER2 $(2+) / H E R 2+$ and HER2 $(2+) /$ HER2 - tumors. Another explanation is the use of different IHC test systems. In other smaller studies with 1150 (Rossi et al. 2012) and 91 (Gilcrease et al. 2009) patients, HER2 $(2+)$ and HER2 $(1+)$ statuses, have also been reported to count as negative prognostic factor for DFS compared to HER2 (0) status.

Our results provide evidence that moderate expression of HER2 $(2+)$ is biologically different from low and negative HER2 $(0 / 1+)$ expression. We believe that the prognostic significance of moderate HER $2(2+)$ expression needs to be reevaluated as a predictor for anti-HER2 therapy. Notably, intratumoral heterogeneity of the HER2 gene is a characteristic property of tumors with low and moderate HER2 expression and is associated with decreased DFS (Barrett et al. 2007, Seol et al. 2012). Therefore, HER2 overexpression without gene amplification should be further evaluated, and the determination of the HER2 status and in particular the predictive value of HER2 $(2+)$ expression should be reconsidered.

The main limitation of the present study is its retrospective character. However, this is a multicenter study with the largest cohort of HER2 $(2+)$ cases to date. Our results suggest that HER2 $(2+)$ tumors have a specific biological behavior associated with an unfavorable clinical outcome. The hypothesis that HER2 $(2+)$ tumors might benefit from an anti-HER2 therapy is going to be addressed in a prospective clinical trial (NSABP-47 trial).

\section{Declaration of interest}

E J Kantelhardt has research funding to disclose from Roche. C Thomssen has consulting and advisory role, honoraria, travel, and accommodations from Astra Zeneca, Roche, Amgen, Novartis, Celgene, and TEVA to disclose. All remaining authors have declared no conflicts of interest.

\section{Funding}

This research did not receive any specific grant from any funding agency in the public, commercial or not-for-profit sector.

\section{References}

Akiyama T, Sudo C, Ogawara H, Toyoshima K \& Yamamoto T 1986 The product of the human c-erbB-2 gene: a 185-kilodalton glycoprotein with tyrosine kinase activity. Science 232 1644-1646. (doi:10.1126/ science.3012781)

Barrett C, Magee H, O'Toole D, Daly S \& Jeffers M 2007 Amplification of the HER2 gene in breast cancers testing $2+$ weak positive by HercepTest immunohistochemistry: false-positive or false-negative immunohistochemistry? Journal of Clinical Pathology 60 690-693. (doi:10.1136/jcp. 2006.039602)

Berry DA, Muss HB, Thor AD, Dressler L, Liu ET, Broadwater G, Budman DR, Henderson IC, Barcos M, Hayes D et al. 2000 HER-2/neu and p53 expression versus tamoxifen resistance in estrogen receptor-positive, node-positive breast cancer. Journal of Clinical Oncology 18 3471-3479.

Camp RL, Dolled-Filhart M, King BL \& Rimm DL 2003 Quantitative analysis of breast cancer tissue microarrays shows that both high and normal levels of HER2 expression are associated with poor outcome. Cancer Research 63 1445-1448.

Gasparini G, Gullick WJ, Maluta S, Dalla PP, Caffo O, Leonardi E, Boracchi P, Pozza F, Lemoine NR \& Bevilacqua P 1994 c-erbB-3 and c-erbB-2 protein expression in node-negative breast carcinoma - an immunocytochemical study. European Journal of Cancer 30A 16-22. (doi:10.1016/S0959-8049(05)80010-3)

Gennari A, Sormani MP, Pronzato P, Puntoni M, Colozza M, Pfeffer U \& Bruzzi P 2008 HER2 status and efficacy of adjuvant anthracyclines in early breast cancer: a pooled analysis of randomized trials. Journal of the National Cancer Institute 100 14-20. (doi:10.1093/jnci/djm252)

Gilcrease MZ, Woodward WA, Nicolas MM, Corley LJ, Fuller GN, Esteva FJ, Tucker SL \& Buchholz TA 2009 Even low-level HER2 expression may be associated with worse outcome in node-positive breast cancer. American Journal of Surgical Pathology 33 759-767. (doi:10.1097/PAS. Ob013e31819437f9)

Goldhirsch A, Winer EP, Coates AS, Gelber RD, Piccart-Gebhart M, Thurlimann B \& Senn HJ 2013 Personalizing the treatment of women with early breast cancer: highlights of the St Gallen International Expert Consensus on the Primary Therapy of Early Breast Cancer 2013. Annals of Oncology 24 2206-2223. (doi:10.1093/annonc/mdt303)

Iorfida M, Dellapasqua S, Bagnardi V, Cardillo A, Rotmensz N, Mastropasqua MG, Bottiglieri L, Goldhirsch A, Viale G \& Colleoni M 2012 HER2-negative $(1+)$ breast cancer with unfavorable prognostic features: to FISH or not to FISH? Annals of Oncology 23 1371-1372. (doi:10.1093/annonc/mds064)

Jacobs TW, Gown AM, Yaziji H, Barnes MJ \& Schnitt SJ 1999 Specificity of HercepTest in determining HER-2/neu status of breast cancers using the

Published by Bioscientifica Ltd. 
United States Food and Drug Administration-approved scoring system. Journal of Clinical Oncology 17 1983-1987.

Massarweh S, Osborne CK, Creighton CJ, Qin L, Tsimelzon A, Huang S, Weiss H, Rimawi M \& Schiff R 2008 Tamoxifen resistance in breast tumors is driven by growth factor receptor signaling with repression of classic estrogen receptor genomic function. Cancer Research $\mathbf{6 8}$ 826-833. (doi:10.1158/0008-5472.CAN-07-2707)

Menard S, Balsari A, Tagliabue E, Camerini T, Casalini P, Bufalino R, Castiglioni F, Carcangiu ML, Gloghini A, Scalone S et al. 2008 Biology, prognosis and response to therapy of breast carcinomas according to HER2 score. Annals of Oncology 19 1706-1712. (doi:10.1093/annonc/ $\operatorname{mdn} 369)$

Minner S, Jessen B, Stiedenroth L, Burandt E, Kollermann J, Mirlacher M, Erbersdobler A, Eichelberg C, Fisch M, Brummendorf TH et al. 2010 Low level HER2 overexpression is associated with rapid tumor cell proliferation and poor prognosis in prostate cancer. Clinical Cancer Research 16 1553-1560. (doi:10.1158/1078-0432.CCR-09-2546)

Paik S, Kim C \& Wolmark N 2008 HER2 status and benefit from adjuvant trastuzumab in breast cancer. New England Journal of Medicine $\mathbf{3 5 8}$ 1409-1411. (doi:10.1056/NEJMc0801440)

Perez EA, Reinholz MM, Hillman DW, Tenner KS, Schroeder MJ, Davidson NE, Martino S, Sledge GW, Harris LN, Gralow JR et al. 2010 HER2 and chromosome 17 effect on patient outcome in the N9831 adjuvant trastuzumab trial. Journal of Clinical Oncology 28 4307-4315. (doi:10.1200/JCO.2009.26.2154)

Ross JS \& Fletcher JA 1998 The HER-2/neu oncogene in breast cancer: prognostic factor, predictive factor, and target for therapy. Oncologist 3 237-252.

Rossi V, Sarotto I, Maggiorotto F, Berchialla P, Kubatzki F, Tomasi N, Redana S, Martinello R, Valabrega G, Aglietta M et al. 2012 Moderate immunohistochemical expression of HER-2 $(2+)$ without HER-2 gene amplification is a negative prognostic factor in early breast cancer. Oncologist 17 1418-1425. (doi:10.1634/theoncologist.2012-0194)
Seol H, Lee HJ, Choi Y, Lee HE, Kim YJ, Kim JH, Kang E, Kim SW \& Park SY 2012 Intratumoral heterogeneity of HER2 gene amplification in breast cancer: its clinicopathological significance. Modern Pathology 25 938-948. (doi:10.1038/modpathol.2012.36)

Slamon DJ, Clark GM, Wong SG, Levin WJ, Ullrich A \& McGuire WL 1987 Human breast cancer: correlation of relapse and survival with amplification of the HER-2/neu oncogene. Science 235 177-182. (doi:10.1126/science.3798106)

Slamon DJ, Godolphin W, Jones LA, Holt JA, Wong SG, Keith DE, Levin WJ, Stuart SG, Udove J \& Ullrich A 1989 Studies of the HER-2/neu protooncogene in human breast and ovarian cancer. Science 244 707-712. (doi:10.1126/science.2470152)

Slamon D, Eiermann W, Robert N, Pienkowski T, Martin M, Press M, Mackey J, Glaspy J, Chan A, Pawlicki M et al. 2011 Adjuvant trastuzumab in HER2-positive breast cancer. New England Journal of Medicine 365 1273-1283. (doi:10.1056/NEJMoa0910383)

Templeton AJ, Diez-Gonzalez L, Ace O, Vera-Badillo F, Seruga B, Jordan J, Amir E, Pandiella A \& Ocana A 2014 Prognostic relevance of receptor tyrosine kinase expression in breast cancer: a meta-analysis. Cancer Treatment Reviews 40 1048-1055. (doi:10.1016/j.ctrv.2014.08.003)

Wolff AC, Hammond ME, Schwartz JN, Hagerty KL, Allred DC, Cote RJ, Dowsett M, Fitzgibbons PL, Hanna WM, Langer A et al. 2007 American Society of Clinical Oncology/College of American Pathologists guideline recommendations for human epidermal growth factor receptor 2 testing in breast cancer. Journal of Clinical Oncology 25 118-145. (doi:10.1200/JCO.2006.09.2775)

Wolff AC, Hammond ME, Hicks DG, Dowsett M, McShane LM, Allison KH, Allred DC, Bartlett JM, Bilous M, Fitzgibbons P et al. 2013 Recommendations for human epidermal growth factor receptor 2 testing in breast cancer: American Society of Clinical Oncology/College of American Pathologists clinical practice guideline update. Journal of Clinical Oncology 31 3997-4013. (doi:10.1200/JCO.2013.50.9984)

Received in final form 5 July 2015

Accepted 14 July 2015

Made available online as an Accepted Preprint

17 July 2015
(C) 2015 Society for Endocrinology Printed in Great Britain 